\title{
Decrease ventilator-associated pneumonia by bundle care in cardiac surgery intensive care unit
}

\author{
CT Hung ${ }^{1 *}$, MH Hsieh ${ }^{1,2}$, P-W Yang ${ }^{1}$, S-W Wu ${ }^{1}$, C-Y Lin ${ }^{1,2}$, Y-H Chen ${ }^{1,2}$ \\ From 3rd International Conference on Prevention and Infection Control (ICPIC 2015) \\ Geneva, Switzerland. 16-19 June 2015
}

\section{Introduction}

Ventilator-associated pneumonia (VAP) is major healthcare-associated infections in intensive care unit (ICU), which increases length of stay, medical cost and mortality.

\section{Objectives}

The infection density of cardiac surgery ICU in a tertiary teaching hospital in southern Taiwan was 4\%o during January 2011 to December 2012 which is higher than $2 \%$ in the other ICUs. In order to decrease the incidence of VAP, bundle care was applied in this ICU.

\section{Methods}

After observing nursing care procedures in 24 intubated patients, some measurements were inappropriate, including mouth care once per day, odor smell in patient's mouth, poor compliance of hand hygiene before and after patient contact, head elevation less than 30 to 45 degrees, no regular evaluation of extubation daily. Therefore, bundle care of VAP with following options was applied, including evaluation of oral hygiene every eight hours, oral hygiene with toothbrush and $2 \%$ chlorhexidine-containing fluid every hour or every eight hours based on individual difference, audit of hand hygiene, reminding symbol for head elevation at bedside, evaluation the necessary of extubation by physician, nurse practitioner and respiratory therapist daily.

\section{Results}

After leading in bundle care and interprofessional practice, the infection density decreased from $4 \%$ during January 2011 to December 2012 to 0\%o during January
2013 to August 2014. The infection density remain zero for twenty months.

\section{Conclusion}

VAP is common healthcare associated infection in ICU and leads to unexpected outcomes in patient care. All the medical staffs should place importance on the concept of bundle care to decrease the incidence of VAP.

\section{Disclosure of interest}

None declared.

\begin{abstract}
Authors' details
${ }^{1}$ Department of Infection Control, Department of Internal Medicine, Kaohsiung Medical University Hospital, Kaohsiung Medical University, Kaohsiung, Taiwan, Province of China. ²Division of Infectious Diseases, Department of Internal Medicine, Kaohsiung Medical University Hospital, Kaohsiung Medical University, Kaohsiung, Taiwan, Province of China.
\end{abstract}

Published: 16 June 2015

\section{References}

1. Mohamed KAE: Compliance with VAP bundle implementation and its effectiveness on surgical and medical sub-population in adult ICU. Egypt. J. Chest Dis. Tuberc 2014, 63(1):9-14.

2. Lerma Álvarez F, García Sánchez M, Lorente L, Gordo F, Añón JM, Álvarez J, Palomar M, García R, Arias S, Vázquez-Calatayud M: Guidelines for the prevention of ventilator-associated pneumonia and their implementation. The Spanish 'Zero-VAP' bundle. Med Intensiva 2014, 38(4):226-236.

doi:10.1186/2047-2994-4-S1-P241

Cite this article as: Hung et al:: Decrease ventilator-associated pneumonia by bundle care in cardiac surgery intensive care unit. Antimicrobial Resistance and Infection Control 2015 4(Suppl 1):P241.

\footnotetext{
${ }^{1}$ Department of Infection Control, Department of Internal Medicine, Kaohsiung Medical University Hospital, Kaohsiung Medical University, Kaohsiung, Taiwan, Province of China

Full list of author information is available at the end of the article
} 